\title{
What Can I Do for You, the Thirsty Planet
}

\author{
Jiatong Song \\ School of North China Electric Power University, Baoding 071000, China. \\ 249521452@qq.com
}

Keywords: Water scarcity; water supply stress index; AHP model.

\begin{abstract}
Water is an essential commodity upon which all life on Earth depends. According to the United Nations, one quarter of the world's population experience water scarcity. Serious water scarcity will block social development and endanger human health .In this paper, I establish model to help figure out the problem of water scarcity. In the first part, I used the analytic hierarchy, by looking at the bottom of the data and determine the weight of each layer to calculate the water demand. In the same way, I can get the total amount of water supply, and with (the water supply, the water demand) for the coordinates of the point in the coordinate system of 1 by 1 square area, I introduce a new parameter - the water stress indicator to divided the square area into several small areas. So that I can determine the extent of water scarcity in the region through the location of the point. In the second part, I chose Shandong Province, China as a severe water shortage area, and chose the Liaoning Province and Jiangxi Province as a comparison, bring the data into the model, by its position validates that our model is correct and universal significance. By substituting the three cities' data in, I found that the results obtained are in good agreement with the water map, which means our model is universal and correct. This model can be used to analyze the current situation of water resources in a region, also can be used to predict future trends. The disadvantage is that the water is a necessity of life, so I ignore the impact of price factors on it, which may cause minor errors.
\end{abstract}

\section{Analysis of the Problem}

If I want to access and predict the situation of water, the reason for the lack of water must be determined. The reason is divided into two sorts. One is physical scarcity, this kind of shortage is because that urban and industrial water demand exceeds the capacity of local water. The other is economic scarcity, Economic scarcity is where water exists but poor management and lack of infrastructure limits the availability of clean water. There is another kind of scarcity, the water in some regions can't reach the domestic water standards because the increasing serious pollution, named pollution-induced water shortage, I divide it into the category of economic scarcity. As for water demand, I divide it into four parts including domestic demand, agriculture demand, industrial demand and ecological demand. There are several factors that constitute each part, and every factor consists of application amount, dissipation amount and emissions. So I can build a model and use all factors that influence demand to calculate total demand in a region. In the case of ignoring price changes, when the supply of water is equal to the demand, they reach an equilibrium. This balance is the ideal state. The status that supply is greater than demand will cause resource waste, named foam of resources. On the other hand, the status that supply is less than demand will lead to water scarcity. Water scarcity is the main problem to be solved in this article.

\section{Assumptions and Justifications}

1 Since water is the necessities of life which is less affected by the price factor. So I ignore the price's influence and only take the balance of demand amount and supply amount into consideration.

2 Assume that all criterion factors meet the requirements of the analytic hierarchy process.

3 Factors that influence result have comprehensiveness. 
4 The dissipation is because of the Evaporation and leakage losses which can't be calculated. And compared with application and emissions, the ratio of the amount of dissipation is small. So I replace its real data with 0.001.Its value after normalization process can be ignored.

\section{Data Pre-processing}

I use the Normalization Process to process the data I need. And the data normalization method I select is the min-max method. I transfer raw data into the new data which fall in the range of $(0,1)$ through the equation 1.Because water demand and supply both are known as positive variable, I only need to consider the size of data.

$\mathrm{y}=(\mathrm{x}-\min ) /(\max -\min )$

Min is the minimum value of $x$, max is the maximum value of $x$, input value is $x$, output value after processing is $\mathrm{y}$.

This kind of processing method can nondimensionalize data. It provides convenience to attach the weight to the data in subsequent models and compare data.

\section{Part 1}

\section{AHP (The Analytic Hierarchy Process) Model}

Water demand can be roughly divided into four parts through the mechanism analysis, domestic demand, agriculture demand, industrial demand and ecological demand included. As for each part,

Demand amount $=$ application amount + dissipation amount + emissions

Therefore, I calculate the amount of water per part based on various empirical formula or find its data directly from website, and AHP Model is adopted to determine its light and integrate all data into one parameter. Then, I can use the parameter to determine the size of wate demand.

As for water supply, the supply of water is divided into natural water supply and technology water supply. Natural water supply consists of surface water supply and ground water supply, and technology water supply consists of storage water, diversion water, lifting water, seawater utilization and so on.

\section{Model design}

1 Establish a hierarchy model

I use the analytic hierarchy process to the water demand. Target level factor is total water demand WDx. There are four vectors in the criterion level including domestic demand, agriculture demand, industrial demand and ecological demand .And I use many programs as the lowest level, such as public supply demand w11,domestic withdrawals w12,irrigation w21, livestock w22,aquaculture w23,thermoelectric power w31, hydroelectric power w32,others w33,river and lake w41, maintenance w42.

2 Construct pairwise comparison judgment matrix, calculate the weight vector and do consistency test.

According to the data I find, agriculture water use accounts for about $62.06 \%$ of total global consumption, while industrial use accounts for about $17.4 \%$, domestic use accounts for $15.77 \%$, and the remaining $4.77 \%$ is used for ecological use. I use these ratio to determine different weights and construct comparison judgment matrix.

Other weight is determined according to the experts' advice. Finally I do consistency test. The steps of consistency test is as follows:

Step 1 Use Matlab software to obtain the maximum eigenvalue of matrix.

Step 2 Calculate the Consistent Index ( C.I. $=\frac{\lambda_{\max }-n}{n-1}$ )

Step 3 Find out corresponding Random Index (R.I.)

Step 4 Determine Consistent Ratio $\left(\right.$ C.R. $\left.=\frac{\text { C.I. } .}{\text { R.I. }}\right)$

The matrix and result of the consistency test is as follows:

Finally I find all C.R.<0.10,so I concluded that the consistent test passed (Table 1). 
Table 1 . The consistent test passed

\begin{tabular}{|c|c|c|c|c|c|c|}
\hline $\mathrm{W}$ & \#1 & $\$ 2$ & \#3 & $\Downarrow 4$ & $\omega_{1}$ & \multirow{5}{*}{$\begin{array}{l}\lambda \cdot \max =4.002 \\
\text { C. I. }=0.0005 \\
\text { C. R. }=0.0006\end{array}$} \\
\hline \#1 & 1 & $2 / 9$ & $2 / 3$ & 2 & $1 / 5$ & \\
\hline \#2 & $9 / 2$ & 1 & 3 & 8 & $5 / 6$ & \\
\hline \#3 & $3 / 2$ & $1 / 3$ & 1 & 3 & $2 / 7$ & \\
\hline ॠ4 & $1 / 2$ & $1 / 8$ & $1 / 3$ & 1 & 0 & \\
\hline
\end{tabular}

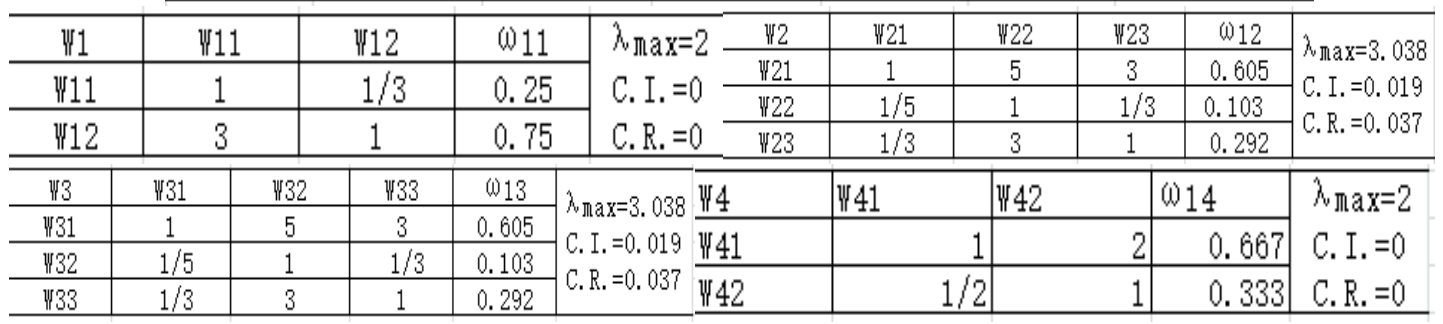

3 Calculate the combined weight vector from the lowest level to the target level

$$
\left[\begin{array}{llll}
0.25 & 0 & 0 & 0 \\
0.75 & 0 & 0 & 0 \\
0 & 0.65 & 0 & 0 \\
0 & 0.103 & 0 & 0 \\
0 & 0.292 & 0 & 0 \\
0 & 0 & 0.605 & 0 \\
0 & 0 & 0.103 & 0 \\
0 & 0 & 0.292 & 0 \\
0 & 0 & 0 & 0.667 \\
0 & 0 & 0 & 0.333
\end{array}\right] \cdot\left[\begin{array}{l}
0.14 \\
0.59 \\
0.21 \\
0.07
\end{array}\right]=\left[\begin{array}{l}
0.0350 \\
0.1050 \\
0.3569 \\
0.0608 \\
0.1723 \\
0.1271 \\
0.0216 \\
0.0613 \\
0.0467 \\
0.0233
\end{array}\right]
$$

Results show the Final ranking vector. I can obtain the function about water demand.

$$
\begin{aligned}
W D_{x}= & 0.0350 W_{11}+0.1050 W_{12}+0.3569 W_{21}+0.0608 W_{22}+0.1723 W_{23} \\
& +0.1271 W_{31}+0.0216 W_{32}+0.0613 W_{33}+0.0467 W_{41}+0.0233 W_{42}
\end{aligned}
$$

Total water supply $=$ Natural water supply + Technology water supply

$$
\text { = Surface Water supply + Ground water supply + other resources }
$$

\section{Result shows}

I establish a cartesian coordinate system, use water supply as $\mathrm{X}$ direction and water demand as $\mathrm{Y}$ direction. I can get a coordinate(WSX,WDX).In this cartesian coordinate system, I draw a $1 \times 1$ square area.(Due to the Normalization Process, and the all weighted sum of data fall into the region (0, 1)).All points on the straight line $y=x$ satisfy the balance between supply and demand. Farther off this line, the more representative of the imbalance of supply and demand of water resources. Thanks to the previous report-An Overview of the State of the World's Fresh and Marine Waters, I acquire a parameter which can express the relation between them ,named Water Supply Stress Index (WaSSIx).

WaSSIx = water demand/water supply

And in this report, I can obtain empirical range (Fig. 1).

WaSSIx $>12.3$ means this region's water scarcity is extremely. (red region)

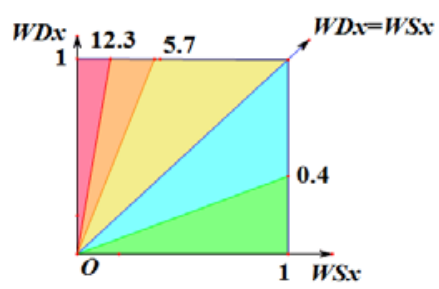

Fig. 1 empirical range

$5.7<$ WaSSIx $<12.3$ means this region's water scarcity is serious. (orange region) 
$1<$ WaSSIx $<5.7$ means this region's water scarcity is obvious. (yellow region)

$0.4<$ WaSSIx $<1$ means this region is not lack of water resources. (blue region)

WaSSIx $<0.4$ means this region is likely to have the phenomenon of resources foam. (green region)

So the $1 \times 1$ square area is divided into five parts. Through drawing the point(WSX,WDX) on the cartesian coordinate system, I could know the situation of this region's water scarcity and compare the difference between several regions.

\section{Part 2}

From water scarcity map given by the United Nations, I selected a serious scarcity region, ShanDong Province, China.Besides, I have selected LiaoNing Province (moderate water shortage) and JiangXi Province (mild water shortage) as a comparison, to verify the accuracy and universality of our model by modeling results of the three provinces.

The following is the water supply data and water demand data after pre-processing in ShanDong Province. Original data are attached to the Appendix, All from the National Statistical Yearbook and Local Statistical Yearbook. Original data Ire substituted into model, drawing the following results:In 2014,water supply in ShanDong Province is 0.58,water demand in ShanDong Province is 4.66,position in the coordinate system is $(0.58,4.66)$.The results show that ShanDong Province is located in zone with serious water shortage.

\section{Conclusion}

The data of other two provinces Ire substituted into model with the same way, and plot points on a coordinate system. From the chart, I can freely draw a conclusion: ShanDong Province is located in the red zone, so it is severe dry land; while LiaoNing Province is located in orange zone, being a medium dry land; and JiangXi Province, the mild dry land, is in the yellow zone. It shows model highly consistent with the United Nations water scarcity map (Fig. 2), telling that our model is correct and can be applied universally.

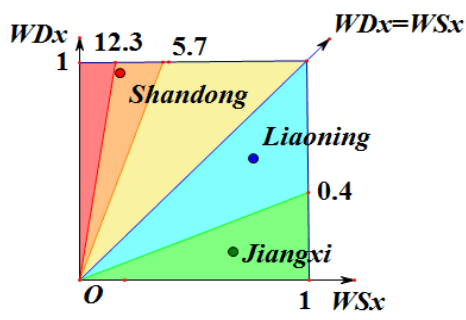

Fig. 2 e model highly consistent with the United Nations water scarcity map

\section{References}

[1] Information on http://www.stats.gov.cn/tjsj/ndsj/

[2] Information on http://www.unep.org/dewa/vitalwater/jpg/0222-waterstress-overuse-EN.jpg

[3] Yifu Sun, Changjun Liu, Jun Zhang. Scientific water resources allocation in Shandong Province

[J]. China Water Resources, 2008, 19:40-42.

[4] Shuhua Yang. Transporting Water from South to North Part and Continuous Utilization of Water Resources in Shandong Province [J].Shandong Land and Resources, 2005, 09:55-57.

[5] Information on http://www.shandong.gov.cn/col/coll350/index.html.

[6] Yanxia Zhang. Analysis and protection measures of water resources in Shandong [J]. Science and Technology of Its China, 2008, 15:58-59.

[7] Hongbin Liu. Solution to the problem of water shortage in Shandong [J]. Territory \&Natural Resources Study, 1996, 04:39-42. 